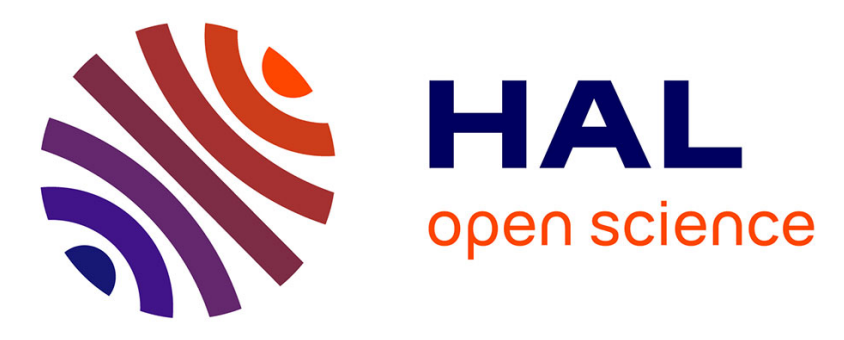

\title{
Synthesis of dense arrays of multiferroic CoFe2O4-PbZr0.52Ti0.48O3 core/shell nanocables
}

David Sallagoïty, Catherine Elissalde, Jérôme Majimel, Mario Maglione, Vlad Antohe, Flavio Miguel Abreu Arojo, Pedro Miguel Pereira de Sá, Sergey Basov, Luc Piraux

\section{To cite this version:}

David Sallagoïty, Catherine Elissalde, Jérôme Majimel, Mario Maglione, Vlad Antohe, et al.. Synthesis of dense arrays of multiferroic CoFe2O4-PbZr0.52Ti0.48O3 core/shell nanocables. RSC Advances, 2016, 6 (108), pp.106716-106722. 10.1039/C6RA19548B . hal-01415912

\section{HAL Id: hal-01415912 \\ https://hal.science/hal-01415912}

Submitted on 19 Feb 2021

HAL is a multi-disciplinary open access archive for the deposit and dissemination of scientific research documents, whether they are published or not. The documents may come from teaching and research institutions in France or abroad, or from public or private research centers.
L'archive ouverte pluridisciplinaire HAL, est destinée au dépôt et à la diffusion de documents scientifiques de niveau recherche, publiés ou non, émanant des établissements d'enseignement et de recherche français ou étrangers, des laboratoires publics ou privés. 


\section{ARTICLE}

Cite this: DOI: 10.1039/x0xx00000x

Received 00th month 2016, Accepted 00th month 2016

DOI:

10.1039/x0xx00000x

www.rsc.org/

\section{Synthesis of dense arrays of multiferroic $\mathrm{CoFe}_{2} \mathrm{O}_{4}-\mathrm{PbZr}_{0.52} \mathrm{Ti}_{0.48} \mathrm{O}_{3}$ core/shell nanocables}

D.Sallagoity $^{a b}$, C. Elissalde ${ }^{a}$, J. Majimel ${ }^{a}$, M. Maglione ${ }^{a}$, Vlad. A. Antohe ${ }^{b}$, F. Abreu Araujo $^{b}$, P. M. Pereira de Sá ${ }^{b}$, S. Basov ${ }^{a b}$, and L. Piraux ${ }^{b}$

A major challenge in the development of efficient magnetoelectric nanocomposites is the adequate control of the interfaces, in order to avoid the formation of undesirable interphases and to ensure an optimal strain mediated coupling. In this work we used a combination of low-cost impregnation and electrodeposition processes within the ordered nanochannels of a porous anodic alumina template, to elaborate $\mathrm{CoFe}_{2} \mathrm{O}_{4}$ $\mathrm{PbZr}_{0.52} \mathrm{Ti}_{0.48} \mathrm{O}_{3}$ core/shell nanocable arrays with high interfacial areas between the ferroelectric and the magnetic phases. We have shown in this way that the thermal annealing steps required for phase's crystallization and oxidation of metallic $\mathrm{CoFe}_{2}$ into spinel $\mathrm{CoFe}_{2} \mathrm{O}_{4}$ are critical with respect to interdiffusion phenomena through the interfaces. The impact of the processing temperature on the morphological and structural features of the nanocables was then discussed. We demonstrated that an optimization of process variables in the synthesis of $\mathrm{CoFe}_{2} \mathrm{O}_{4}-\mathrm{PbZr}_{0.52} \mathrm{Ti}_{0.48} \mathrm{O}_{3}$ nanocables allows a significant improvement in their microstructure and ensures the chemical integrity of the two-phase materials, an important concern when seeking for enhanced multiferroic properties. 


\section{ARTICLE}

\section{Introduction}

Magnetoelectric (ME) composites made by combining ferroelectric and magnetic phases are a novel class of next generation multifunctional materials that have drawn significant interest in recent years ${ }^{1,2,3,4,5,6}$. In particular, the indirect strain mediated coupling interaction between piezoelectric and magnetostrictive phases could produce a large ME response, several orders of magnitude higher than that corresponding to single phase ME materials so far available at room temperature. This ME effect in composite materials is known as a product tensor property which results from the cross interaction between piezoelectric and magnetostrictive ordering of the two phases ${ }^{1}$. ME composite architectures have been elaborated in several geometries like particles embedded in a matrix ${ }^{7,8}$, co-sintered bilayered structures ${ }^{9,10,11}$, as well as low-dimensionality heterostructures such as laminated and epitaxial auto-assembled vertical thin films ${ }^{12,13,14,15}$ or more recently, coaxial nanofibers ${ }^{16,17,18}$.

There is also a significant interest in the use of templateassisted synthesis methods due to their proven reliability, flexibility and reproducibility in order to build well-ordered tridimensional arrays of nanocables (NCs) with high aspect ratio and high surface areas $19,20,21,22,23,24$. In a previous work ${ }^{25}$, we reported the two-step elaboration of $\mathrm{Ni}^{-\mathrm{BaTiO}_{3}}(\mathrm{Ni}-\mathrm{BTO}) \mathrm{NC}$ arrays within porous anodic aluminum oxide (AAO) templates and we pointed out the limitations inherent to annealing temperature ${ }^{26,27}$. Thermal treatment performed at too high temperature: i) may affect the ferroelectric BTO shell microstructure through defects-driven surface rearrangement and interdiffusion inside the AAO pores, or it ii) may induce the template curvature and hence hinder the subsequent $\mathrm{Ni}$ electrodeposition into the BTO-coated AAO pores. Meanwhile, composites made of $\mathrm{CoFe}_{2} \mathrm{O}_{4}-\mathrm{Pb}\left(\mathrm{Zr}_{0.52} \mathrm{Ti}_{0.48}\right) \mathrm{O}_{3}$ (CFO-PZT) are very appealing, as PZT with composition near the morphotropic phase boundary (MPB) exhibits excellent ferroelectric and piezoelectric properties, whereas $\mathrm{CFO}$ displays large magnetocrystalline anisotropy, high coercivity, and moderate saturation magnetization ${ }^{1}$. Most of the studies devoted to PZT/CFO are based on electrospinning ${ }^{28,29,30}$. Here we propose to built vertically oriented arrays of CFO-PZT NCs using a threestep process: i) sol-gel impregnation of AAO templates and crystallization of the PZT shell on the pore walls, thus forming PZT nanotubes (NTs) ii) $\mathrm{CoFe}_{2}$ (CF) metallic alloy electrodeposition within the PZT-coated AAO templates and iii) in-situ oxidation of the CF to obtain the desired CFO spinel cores. These processes are schematically illustrated in Fig. 1. Compared to the Ni-BTO NCs, the synthesis of CFO-PZT NCs implies an additional critical step consisting of an in-situ oxidation process to reach the final magnetostrictive spinel phase. Taking into account the above-mentioned temperaturerelated limitations, the optimal thermal energy required for material crystallization should be thus carefully considered.

In the present work, we studied the fabrication of CFO-PZT core-shell NCs within AAO, focusing on the annealing temperature effects. We showed the role of the PZT NTs as a diffusion barrier and the benefit of the direct in-situ oxidation of metallic CF Nws into CFO during the crystallization of NTs with regards to interface control. We took advantage of the flexibility of the combined impregnation-electrodeposition approach to lower the process temperature and to design nanocable with improved microstructure while ensuring a significant improvement in their microstructure and ensures the chemical integrity of the two-phase materials, an important concern when seeking for enhanced multiferroic properties.

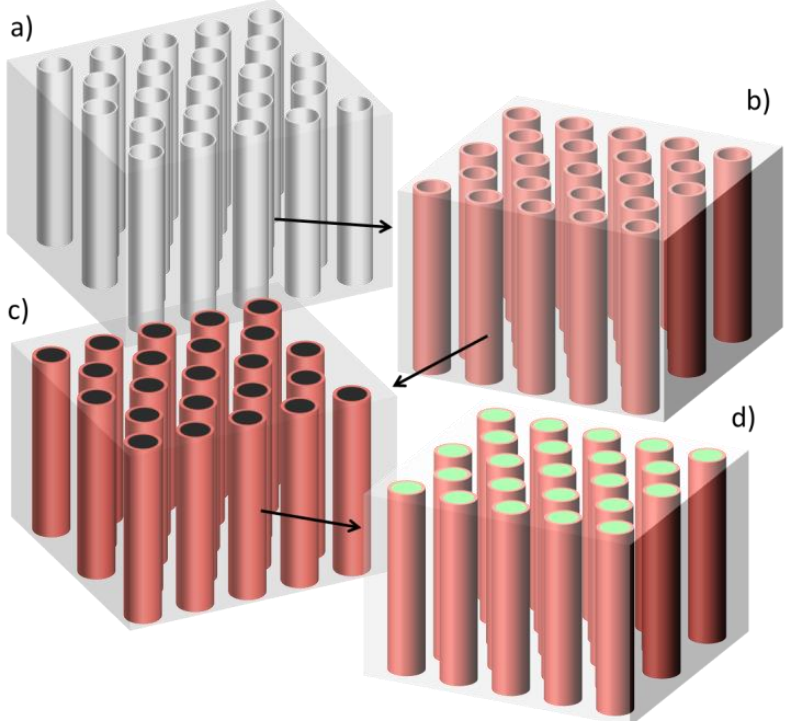

Figure. 1. (Color online) Schematics for the synthesis of the CFO-PZT NC arrays: a) porous AAO template, b) wet chemical deposition and cryztallisation of the PZT shells on the AAO pore walls, c) electrodeposition of the $C F$ cores within the PZT-coated AAO pores, and d) CF conversion into CFO by in-situ thermal oxydation.

\section{Experimental section}

Commercial AAO templates (Synkera Technology Inc., Longmont, CO, USA) were used as the nanoporous host for the process development. They featured a thickness of $50 \mu \mathrm{m}$ with a mean pore diameter of $150 \mathrm{~nm}$ and an inter-pore distance (centerto-center distance between pores) around 250-300 nm, leading thus to a porosity of $\sim 15 \%$.

The PZT sol was synthesized using lead acetate trihydrate $\mathrm{Pb}\left(\mathrm{CH}_{3} \mathrm{CO}_{2}\right)_{2} 3 \mathrm{H}_{2} \mathrm{O}$ and titanium (IV) isopropoxide $\mathrm{Ti}\left(\mathrm{OCH}\left(\mathrm{CH}_{3}\right)_{2}\right)$ from Sigma Aldrich, as well as zirconium (IV) isopropoxide $\mathrm{Zr}\left(\mathrm{OCH}\left(\mathrm{CH}_{3}\right)_{2}\right) 70 \%$ wt. from Alpha Caesar as precursors $^{31}$. Lead acetate trihydrate $\mathrm{Pb}\left(\mathrm{CH}_{3} \mathrm{CO}_{2}\right)_{2} 3 \mathrm{H}_{2} \mathrm{O}$ was dissolved separately in glacial acetic acid at room temperature under magnetic stirring. $\mathrm{Ti}$ and $\mathrm{Zr}$ were dispersed in a second vessel containing isopropanol at room temperature under stirring. Then the two solutions were mixed under stirring at room temperature to form an homogeneous $0.4 \mathrm{M}$ stoichiometric MPB $\mathrm{PbZr}_{0.52} \mathrm{Ti}_{0.48} \mathrm{O}_{3}$ sol. Water was added in the mixture to activate the complete hydrolysis of the alkoxydes. AAO templates were immersed into the PZT sol during one minute. Wet faces were carefully dried with absorbent paper to remove the PZT film formed on the top, prior to the crystallization annealing. Two calcination temperatures for PZT crystallization were selected, i.e. $500^{\circ} \mathrm{C}$ and $700^{\circ} \mathrm{C}$ (referred to as $\mathrm{PZT}^{500}$ and $\mathrm{PZT}^{700}$ in the following) during $6 \mathrm{~h}$ in order to ensure complete crystallization of the PZT while preventing phase transformation of the amorphous alumina into $\alpha-\mathrm{Al}_{2} \mathrm{O}_{3}{ }^{25}$.

Next, arrays of CF-PZT NCs have been fabricated by electrodeposition using a three-electrode potentiostatic setup with a Pt foil acting as counter electrode. The working electrode consisted of a Cu/Au (900/100 nm) bilayer subsequently 
evaporated onto one side of the PZT-impregnated AAO template to cover its pores. The CF metallic cores were then grown at room temperature, by applying a pulsed potential (oscillating between $-1.5 \mathrm{~V}$ for $80 \mathrm{~ms}$ and $-0.5 \mathrm{~V}$ for $20 \mathrm{~ms}$ ) versus an $\mathrm{Ag} / \mathrm{AgCl}$ reference electrode ( $\mathrm{KCl}$ saturated), in an electrolyte containing $0.1 \mathrm{M} \mathrm{FeSO}_{4} \cdot 6 \mathrm{H}_{2} \mathrm{O}, 0.1 \mathrm{M} \mathrm{CoSO}_{4} \cdot 6 \mathrm{H}_{2} \mathrm{O}$ and $0.16 \mathrm{M}$ $\mathrm{H}_{3} \mathrm{BO}_{3}$. The plating current was recorded as a function of time and the electrodeposition process was stopped before filling the PZT-coated AAO nanopores to preserve the one-dimensional core/shell CF-PZT structure considering the large volume expansion along the pore axis after metal deposition. The height of electrodeposited CF nanowires was thus limited to $10 \mu \mathrm{m}$. Ultimately, the dense arrays of CFO-PZT NCs were obtained after a subsequent annealing treatment at $500^{\circ} \mathrm{C}$ or $600^{\circ} \mathrm{C}$ for 24 $\mathrm{h}$ in air (referred to in the text as $\mathrm{CFO}^{500}$ or $\mathrm{CFO}^{600}$, respectively).

First, morphological and structural characterization was performed after each processing step, using either scanning electron microscopy (HRSEM and STEM-BF) and/or in-situ Xray Diffraction (XRD). Second, magnetic characterization of the AAO-embedded core/shell NCs was carried out before and after the different thermal exposures, using a Superconducting Quantum Interference Device (SQUID) and/or an Alternating Gradient force Magnetometer (AGFM).

\section{Results and discussion}

\section{PZT shell crystallization}

HRSEM investigations were carried out to check PZT ${ }^{700}$ and $\mathrm{PZT}^{500}$ morphology and nanostructuration after the subsequent removal of the AAO template in a $1 \mathrm{M} \mathrm{NaOH}$ (aq.) solution (Fig. 2 ). In both cases, bundle of PZT tubular high aspect-ratio nanostructures were observed, driven by strong interactions between their hydrophilic surfaces. The amount of residual AAO $\left(\tau_{A l}\right)$ remained on their surfaces after the template removal was estimated from Energy Dispersive X-ray (EDX) analysis, according to the following equation:

$$
\tau_{A l}=\frac{a t . \%_{A l}}{a t . \%_{(P b+T i+Z r)}}
$$

The obtained $\tau_{A l}$ mean value of 3 for $\mathrm{PZT}^{700}$ indicates that the etching process does not allow to fully remove the AAO for the sample annealed at $700^{\circ} \mathrm{C}$. This is supported by the fact that the $\mathrm{PZT}^{700}$ tubular structures were rough and granular as shown in Figs. 2 (a) and (b)
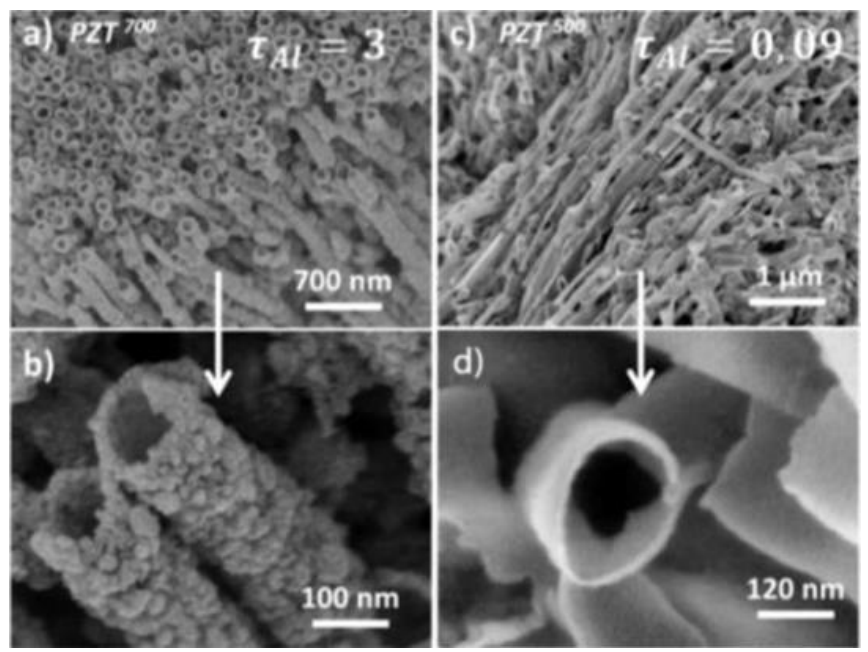

Figure. 2. HRSEM micrographs showing bundles of PZT ${ }^{700}$ (a) and $\mathrm{PZT}^{500}$ (c) tubular structures after the AAO template removal. (b, d) Corresponding higher magnification images. The pronounced granular aspect of the $\mathrm{PZT}^{700}$ structures can be observed in panel (b).
Compared to BTO, PZT is a complex ternary system, and metastable binary oxides such as $\mathrm{PbO}, \mathrm{PbO}_{2}, \mathrm{ZrO}_{2}, \mathrm{TiO}_{2}$, can be formed during the pyrolysis reaction occurring in the temperature range of $300-400^{\circ} \mathrm{C}$. The volatility of $\mathrm{PbO}$ is also a recurring issue. In contrast, it was shown that annealing temperatures up to $700^{\circ} \mathrm{C}$ carry enough energy to induce $\mathrm{Pb}$ diffusion into AAO through oxygen vacancies ${ }^{32}$. This phenomenon may thus promote crystallized interphases formation of $\mathrm{Pb}_{2} \mathrm{Al}_{2} \mathrm{O}_{5}, \mathrm{PbAl}_{12} \mathrm{O}_{19}$ or $\mathrm{Al}_{2} \mathrm{TiO}_{5}$ (Fig. 3 (a)).

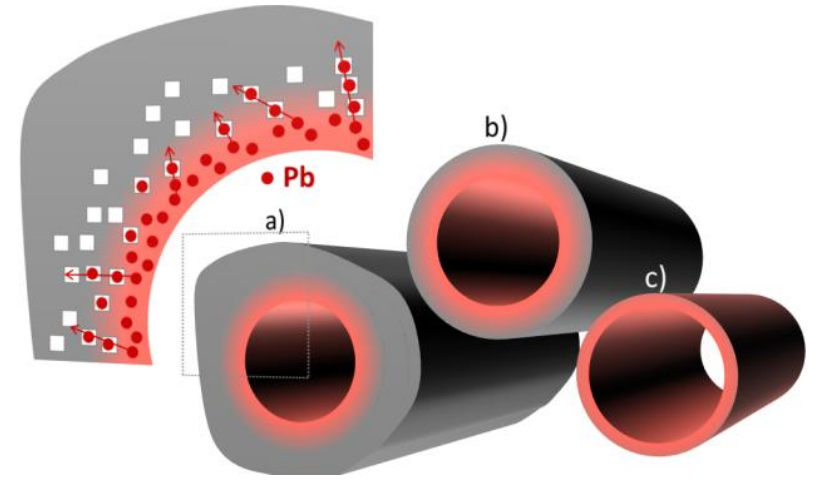

Figure. 3. (Color online) a) Schematic illustrations of the $\mathrm{Pb}$ Al interphase formation during PZT crystallization at $700^{\circ} \mathrm{C}$ for $6 \mathrm{~h}$ inside the AAO template. The inset shows a magnified view at the interface between the two constituents, highglighting the diffusion process of $\mathrm{Pb}$ into the amorphous AAO. b) A single $\mathrm{PZT}^{700}$ tubular structure obtained after the chemical dissolution of the AAO template, consisting in a tubular core/shell PZT/AAO system. c) A single AAO-free $\mathrm{PZT}^{700}$ tubular structure after a $5 \mathrm{M} \mu$-wave etching step.

Considering the small amount of PZT NTs and the complex diffusion process, thermogravimetric and XRD analyses did not allow a reliable identification and discrimination of interphases. However the presence of residual amorphous Al and Al-rich crystallized phases were unambiguously detected by HRSEM. From the microstructural analysis, we can thus deduce that i) partially crystallized Al-rich interphase is formed under crystallization conditions at $700^{\circ} \mathrm{C}$ for $6 \mathrm{~h}$, and ii) the $\mathrm{AAO}$ interphase cannot be fully removed using $1 \mathrm{M} \mathrm{NaOH}$ (aq.) wet etching conditions. Consequently, the $\mathrm{PZT}^{700}$ nanostructures revealed in these soft conditions consist in a tubular double-shell mixture of Al-rich interphases at the outer surface and pure PZT inside (as illustrated in Fig. 3 (b)). Their high surface roughness (see Fig. 2(b)) can be thus explained by the formation of a granular shell made of Al-rich phase. Dissolution process was then performed in extreme conditions $(5 \mathrm{M} \mathrm{NaOH}$ under $\mu$-wave at $160^{\circ} \mathrm{C}$, followed by an ultrasonic dispersion in ethanol) in order to unambiguously evaluate $\mathrm{PZT}^{700}$ inner nanostructure (schematic representation in Fig. 3 (c)). In comparison, PZT $^{500}$ structures crystallized at lower temperature $\left(500^{\circ} \mathrm{C}\right)$ have thinner walls and present smooth and homogeneous surface after the AAO wet etching step (see Figs. 2 (c) and (d)). The thickness of the PZT nanotubes was estimated close to $15 \mathrm{~nm}$ by STEM-EDX analysis. The mean $\tau_{A l}$ value calculated close to 0.1 indicates that the residual AAO was entirely removed and the formation of Alrich interphase was prevented. As a result, pure $\mathrm{PZT}^{500}$ tubular structures with smooth outer surfaces were observed (see Fig. $2(d))$.

\section{CF electrodeposition within PZT-coated AAO and subsequent thermal conversion into $\mathrm{CFO}$}

Figs. 4 (a) and (b) show cross-sectional views at two different magnifications through an array of CF-PZT ${ }^{700}$ NCs embedded in the AAO template. The filling of the PZT was homogeneous and 
the $\mathrm{CF}$ growth was stopped when the deposited height was about $10 \mu \mathrm{m}$. As expected, starting from the top three distinct phases are thus clearly evidenced (see Fig. 4 (a)): the porous alumina template (dark grey), the PZT-coated AAO pores region (light gray) and the electrochemically-grown area of metallic $\mathrm{CF}$ solid cores (white). Such ordered arrays of AAO-embedded CF-PZT NCs were magnetically characterized to determine the impact of the $\mathrm{NC}$ architecture on the magnetic properties.
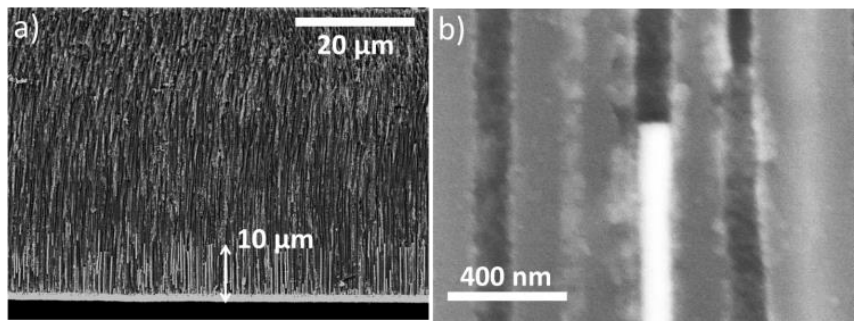

Figure. 4. (a) HRSEM fracture image of a CF-PZT ${ }^{700}$ nanocable array embedded in the AAO template $(150 \mathrm{~nm}$ pore diameter, $15 \%$ porosity). (b) Corresponding closed-up magnification of a single $\mathrm{NC}$ highlighting the three-phased AAO-PZT-CF morphology.

For the arrays of metallic CF nanowires, the magnetocrystalline anisotropy can be neglected and the effective field $H_{\text {eff }}$ in the saturated state is only determined by magnetostatic contributions, i.e. shape anisotropy and dipolar interaction. It can be thus expressed as ${ }^{33}$.

$$
H_{e f f}=2 \pi M_{S}-6 \pi M_{S} P
$$

where $2 \pi M_{S}$ is the shape anisotropy, $6 \pi M_{S} P$ is the dipolar interaction field in the saturated state, with $\mathrm{P}$ the nanowire packing factor (corresponding to the template porosity, i.e. $15 \%$, in case the whole cross section of the nanochannel array of the pristine AAO template is completely filled by $\mathrm{CF}$ ) and $M_{S}=$ $1850 \mathrm{emu} \cdot \mathrm{cm}^{-3}$ is the saturation magnetization for CF. For comparison, an array of $\mathrm{CF}$ nanowires was prepared using the same electrochemical conditions and porous AAO template. Fig. 5 shows the normalized SQUID hysteresis loops measured at room temperature with the field applied along the revolution axis of the nanowires for the two samples (AAO-embedded $\mathrm{CF}$ nanowires and CF-PZT core/shell NCs).

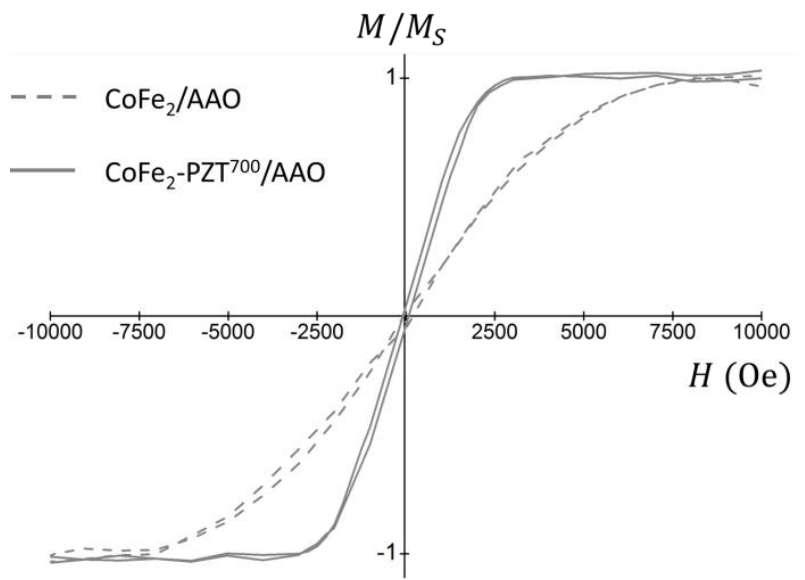

Figure. 5. Room temperature hysteresis loops measured with the external field applied along the revolution axis of the AAO-embedded CF nanowires (dashed line) and CF-PZT ${ }^{700}$ NCs (solid line).

As expected, the PZT-CF NCs sample is more easily magnetized than the $\mathrm{CF}$ nanowire sample counterpart. This is because of the $\mathrm{NC}$ morphology, which leads to a packing factor for the CF-PZT system smaller than for the purely metallic nanowire sample. As a result, the interaction field is smaller and leads to higher effective field and a stronger uniaxial anisotropy in the core/shell NCs. In contrast, the higher packing value of CF nanowires results in stronger dipolar interactions which are responsible for the shearing of the hysteresis loop ${ }^{34}$.

Recent papers reported the high reactivity of amorphous AAO in contact with metallic nanowires when increasing temperature, through the so called Kirkendall effect ${ }^{35,36,37}$. Our preliminary oxidation tests performed at $600^{\circ} \mathrm{C}$ during $24 \mathrm{~h}$ in air (corresponding to the usual conditions reported in most papers from literature ${ }^{38,39,40,41,42}$ ) within pure AAO templates have shown strong interdiffusion effects between $\mathrm{Co}, \mathrm{Fe}$ and $\mathrm{Al}$, and the formation of an Al-rich interphase between $\mathrm{CFO}^{600}$ oxidized nanowires and AAO. However, when considering $\mathrm{PZT}^{700}$ within AAO membranes, the reactivity between AAO and CF seems to be stabilized thanks to the PZT shell which acts as an efficient diffusion barrier layer. Figs. 6 (a) and (b) show HRSEM images of oxidized $\mathrm{CFO}^{600}-\mathrm{PZT}^{700} \mathrm{NCs}$ after chemical dissolution of the template, revealing that the core/shell morphology has been maintained after the CF oxidation process.

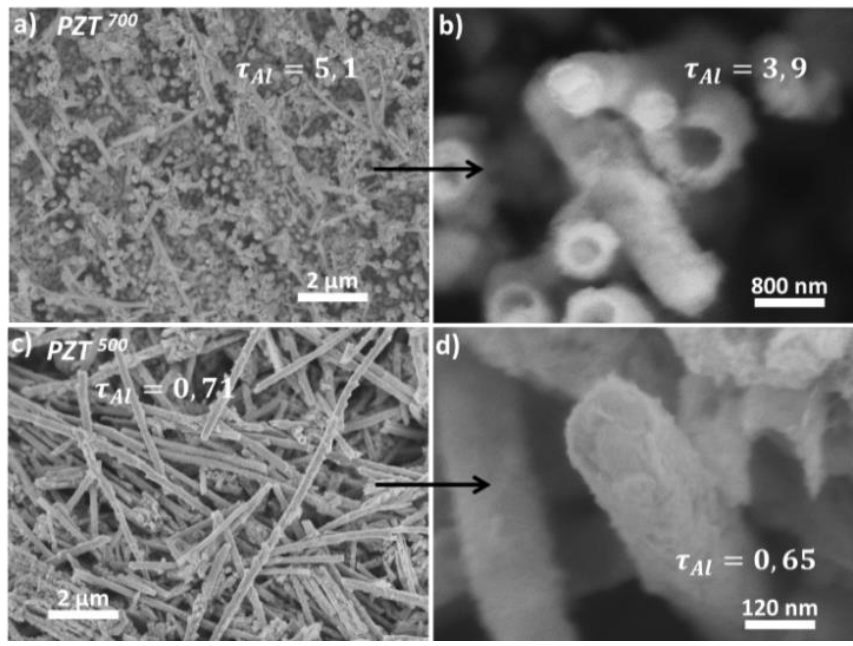

Figure. 6. (a, b) HRSEM micrographs at different magnifications, showing the dense arrays of $\mathrm{CFO}^{600}-\mathrm{PZT}^{700}$ NCs after the AAO template etching in $1 \mathrm{M} \mathrm{NaOH}$. (c, d) Micrographs at different magnifications acquired from the CFO $^{500}$ PZT $^{500}$ NCs prepared in similar conditions.

Mean $\tau_{A l}$ values for oxidized CFO ${ }^{600}-\mathrm{PZT}^{700} \mathrm{NCs}$ were typically measured between 3.9 and 5.1. The oxidation step is thus followed by a significant increase of residual AAO in comparison with the $\mathrm{PZT}^{700}$ tubular structures (see Figs. 2 (a) and (b)). In other words, interdiffusion between PZT shell and AAO template is enhanced during the second thermal treatment for converting $\mathrm{CF}$ into $\mathrm{CFO}$ at $600^{\circ} \mathrm{C}$.

Bright field (BF) STEM experiments coupled with EDX compositional mapping were performed on $\mathrm{CFO}^{600}-\mathrm{PZT}^{700} \mathrm{NCs}$ following two different protocols for the sample preparation 
(Fig. 7). The elementary analysis evidences atomic diffusion of $\mathrm{Pb}$ inside the AAO template (Fig. 7 (b)) and the presence of Alrich crystallized interphase on the surface of single free NCs obtained after $\mathrm{NaOH}$ etching (Fig. 7 (c) and (d)). As expected, the decrease of both PZT crystallization temperature from $700^{\circ} \mathrm{C}$ to $500^{\circ} \mathrm{C}$ and $\mathrm{CF}$ to $\mathrm{CFO}$ oxidation temperature from $600^{\circ} \mathrm{C}$ to $500^{\circ} \mathrm{C}$ leads to a significant decrease of $\tau_{A l}$ values (approximatively divided by 5 with respect to $\mathrm{CFO}^{600}-\mathrm{PZT}^{700}$ see Figs. 6 (c) and (d)). Similarly, the surface of free $\mathrm{CFO}^{500}$ PZT $^{500}$ NC observed by STEM-BF after AAO template etching in $1 \mathrm{M} \mathrm{NaOH}$ (aq.) and dispersion in ethanol is smooth and well defined (see Figs. 7. (e) and (f)).

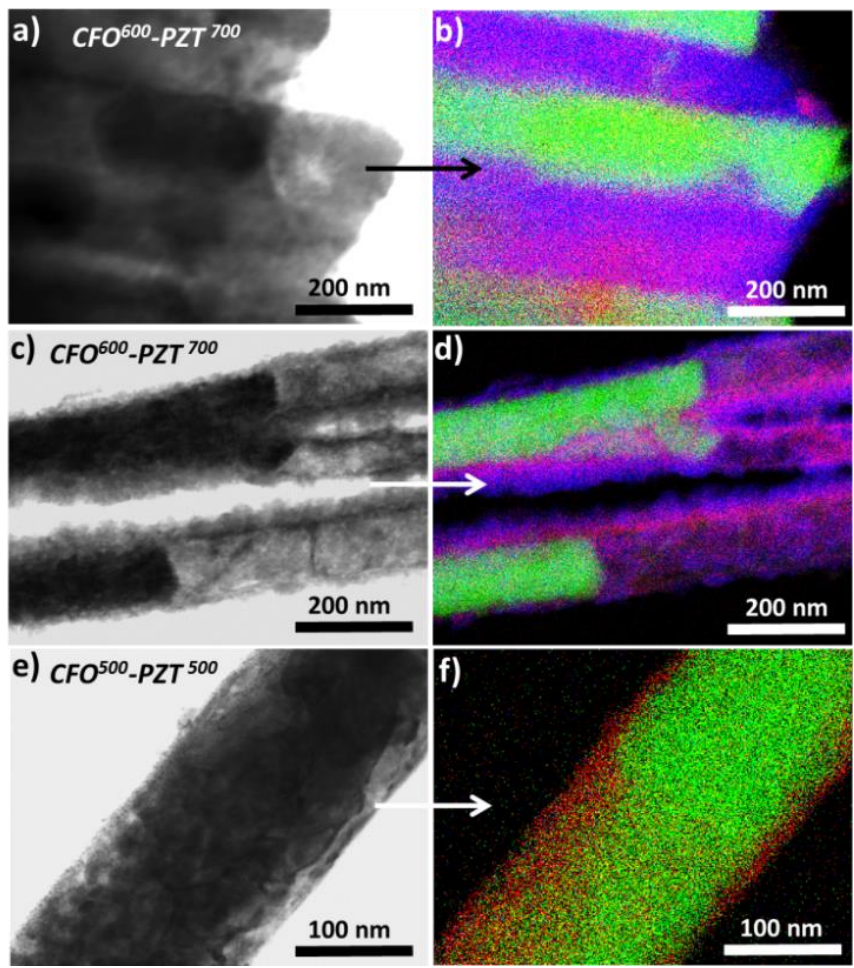

Figure. 7. (Color online) (a) STEM-BF micrograph of the CFO $^{600}$.PZT $^{700}$ core/shell architecture within the AAO template after grinding and dispersion in ethanol. (c) The same sample after $\mathrm{AAO}$ etching in $1 \mathrm{M} \mathrm{NaOH}$ and dispersion in ethanol. (e) The $\mathrm{CFO}^{500} \mathrm{PZT}^{500}$ system after template etching and dispersion in ethanol. (b, d, f) Corresponding chemical mapping, with $\mathrm{Pb}, \mathrm{Fe}$ and $\mathrm{Al}$ represented in red, green and blue, respectively.

Accordingly, no contribution of $\mathrm{Al}$ (expected to appear in blue color on the chemical mapping image) occurs in such optimized annealing conditions. Therefore, from the electron microscopy investigations, it clearly appears that reduction of the temperature of crystallization of the PZT shells and of the temperature of metallic cores oxidation, leads to a significant improvement of both morphological and structural characteristics of the CFO-PZT core/shell assembly.

To further support the latter statements, $\mathrm{CF}$ to $\mathrm{CFO}$ oxidation inside pre-annealed PZT ${ }^{500}$ tubular structures was followed by in situ X-ray diffraction using a PANalytical diffractometer with cobalt anticathode (see Fig. 8). Taking into account the very low quantity of matter inside the AAO template and the strong nanostructuration of the phases (either for PZT shell or for CF core), specific preparation technics were developed in order to accurately and unambiguously determine the structural features of the CFO-PZT NCs. A PZT multi-impregnation process (three successive impregnations with intermediate crystallization steps) was carried out to provide thick enough tubular structures.
Electrodeposition step was maintained longer to increase the CF height. The cubic CF (110) most intensive peak $\left(52.4^{\circ}\right.$ for Co anticathode) represented by the black dotted line is surrounded by two peaks very close, attributed to PZT and $\mathrm{Au}$ (contribution of the $\mathrm{Cu} / \mathrm{Au}$ bilayer cathode used for electrodeposition). However, the contribution of each phase can be easily discriminated when increasing the temperature. Progressive disappearance of the $\mathrm{CF}$ (110) peak is observed between $20^{\circ} \mathrm{C}$ and $500^{\circ} \mathrm{C}$ whereas $\mathrm{CFO}$ spinel phase starts to crystallize at $300^{\circ} \mathrm{C}$ (green marked peaks (220),(311), (400), (511), and (440) at $35.7^{\circ}, 41.6^{\circ}, 50.7^{\circ}, 63.0^{\circ}, 67.5^{\circ}$ and $74.4^{\circ}$, respectively).

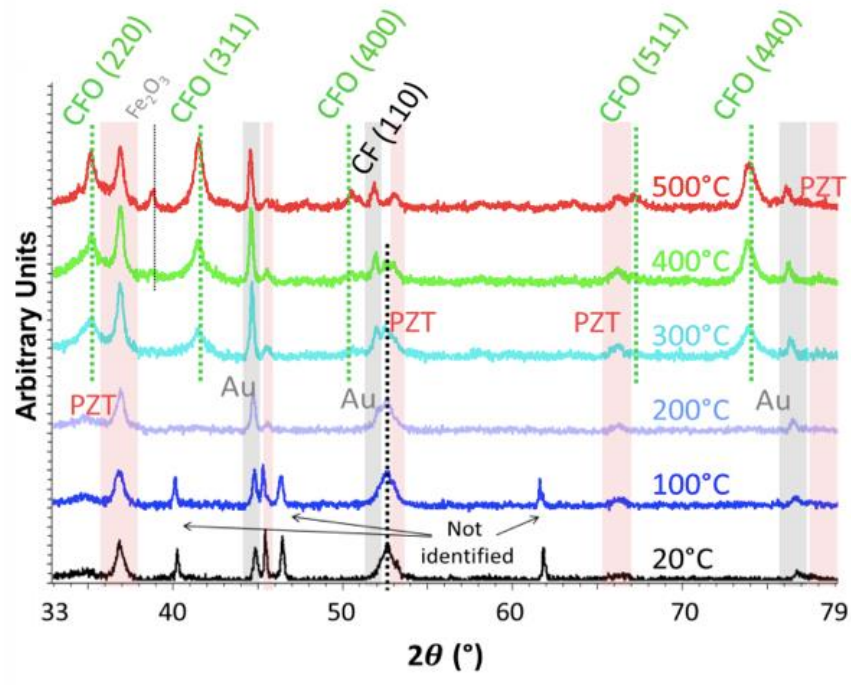

Figure. 8. (Color online) CF to CFO in-situ oxidation inside PZT followed by in-situ X-ray diffraction at different temperatures with an increment of $100^{\circ} \mathrm{C}$. The starting room temperature $\mathrm{CF}$ pattern is represented in black and the final CFO oxidized one is in red.

This evolution indicates that the metallic $\mathrm{CF}$ and the oxide $\mathrm{CFO}$ coexist over a temperature range going from $300^{\circ} \mathrm{C}$ to $500^{\circ} \mathrm{C}$. The intensity of spinel CFO peaks increases with temperature while the mid-height width decreases, in good agreement with a gradual increase in the crystalline size within the oxidized cores. Moreover, relative intensities of (220) $\left(35.7^{\circ}\right)$ and (440) $\left(74.4^{\circ}\right)$ peaks are raised meaning a preferential orientation of the CFO phase along (hk0) plans, possibly attributed to the highly anisotropic confinement given by the porous structure of the AAO template. We can then assume that $\mathrm{CF}$ to $\mathrm{CFO}$ oxidation should be effective at lower temperature than $600^{\circ} \mathrm{C}$. In addition PZT $^{500}$ crystalline signature is evidenced by the presence of five peaks (marked in red on Fig. 8) that are attributed to a pseudocubic phase of $\mathrm{Pb}(\mathrm{ZrTi}) \mathrm{O}_{3}$, as confirmed by profile matching using EVA software. HRTEM investigation conducted on PZT NTs (not shown) confirmed the high crystallinity of PZT nanoparticles (mean diameter ranging between 5 and $10 \mathrm{~nm}$ ). This size belongs to the critical range with regards to the alteration of ferroelectricity. However, it was clearly shown in literature that in confined 1D geometry, the contribution of defects, surface tension, strain induced domain configuration, effective screening of the surfaces charges by chemisorbed hydroxyl groups could locally stabilize a polar state ${ }^{43,44,45}$.

Fig. 9 shows the magnetic hysteresis curves with the external field applied parallel to the $\mathrm{NC}$ axis. For the CF nanowire arrays, magnetocrystalline anisotropy can be neglected and the effective anisotropy is entirely magnetostatic, as pointed out previously. In contrast, large coercivity fields and remanence have been achieved in the CFO nanowire arrays. Such high coercive fields are associated with the magnetocrystalline anisotropy, and also possibly since the grain size is approaching the single-domain 
critical value ${ }^{38}$. The results show that oxidation performed at $600^{\circ} \mathrm{C}$ during $24 \mathrm{~h}$ under air is followed by a significant decrease of the saturation magnetic moment by a factor 3.8 and by a large increase of the coercive field from few tens of Oe to 1100 Oe (Fig. 9 (a))

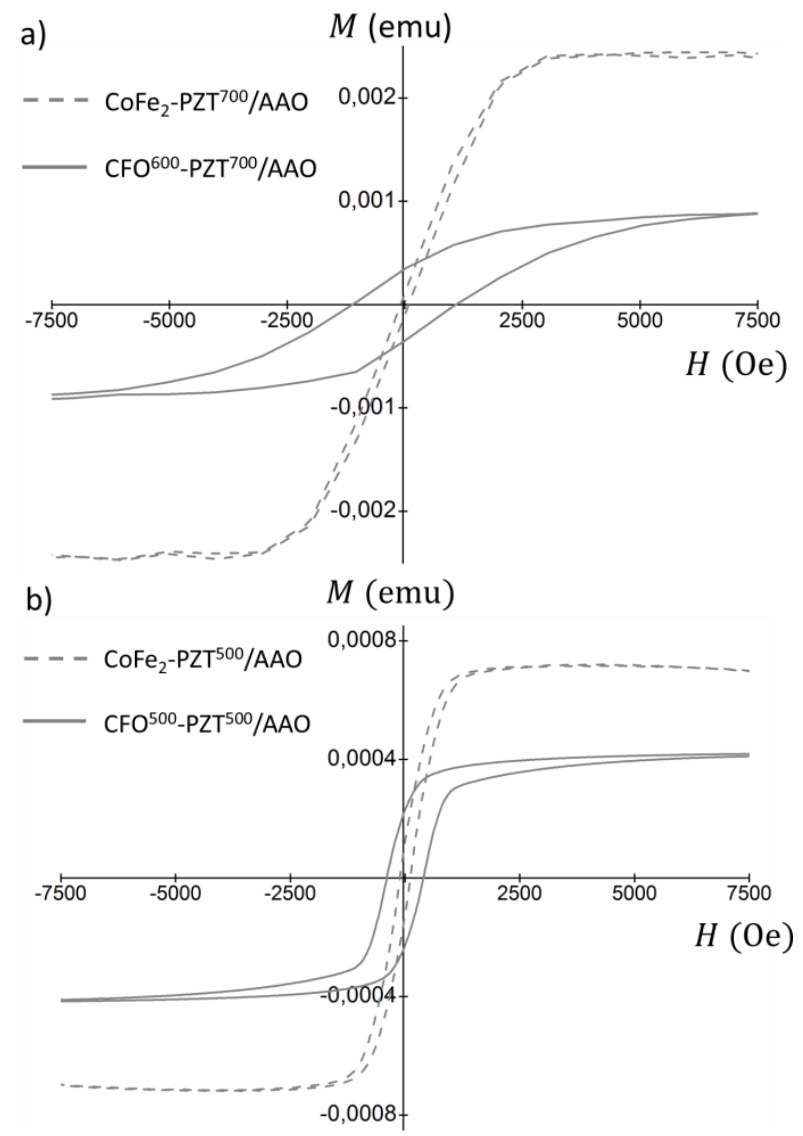

Figure. 9. (Color online) a) Room temperature hysteresis loops measured with the external field applied along the revolution axis of the CF-PZT ${ }^{700} \mathrm{NCs}$ (dashed line) and $\mathrm{CFO}^{600} \mathrm{PZT}^{700} \mathrm{NCs}$ (solid line) embedded in AAO templates, b) the same as in a) for CF-PZT ${ }^{500} \mathrm{NCs}$ (dashed line) and CFO $^{500-P_{2 T}}{ }^{500}$ NCs (solid line)

As shown in Fig. 9 (b), oxidation at a lower temperature $\left(500^{\circ} \mathrm{C}\right)$ leads to a somewhat smaller reduction in the saturation magnetic moment (a factor 2.5) and coercive field (around $450 \mathrm{Oe}$ ). The coercive fields are comparable to the room temperature values reported in the literature for CFO/AAO systems ${ }^{38,39,40,41,42}$.

\section{Conclusions}

CFO-PZT NCs were successfully synthesized combining the cost effective impregnation and electrodeposition processes. The thermal treatment required to obtain the magnetostrictive spinel phase is a key step with respect to the interdiffusion phenomena. We showed that the PZT act as an efficient diffusion barrier between the CF cores and the AAO template. We overcame the thermal constraints and demonstrated the benefit of a global lowering of the processing temperature to preserve both architecture and structural integrity of this complex system. Such control of interfaces opens a promising pathway towards lowcost processing of magnetoelectric nanocomposites.

\section{Acknowledgements}

F.A.A. acknowledges the Research Science Foundation of Belgium (FRS-FNRS) for financial support (FRIA grant). The
IDS FunMat European doctoral school is also acknowledged for financial support. The work was partially supported as well by the Fédération Wallonie-Bruxelles (ARC 13/18-052 Supracryst).

\section{Notes}

${ }^{a}$ CNRS, Univ. Bordeaux, ICMCB, UPR 9048, 87 Avenue du Docteur Schweitzer, 33600 Pessac, France.

${ }^{b}$ Institute of Condensed Matter and Nanosciences, Université catholique de Louvain, Place Croix du Sud, B-1348, Louvain-la-Neuve, Belgium.

${ }^{c}$ ICGM-UMR5253, Université Montpellier II, 2 Place Eugène Bataillon, CC 1502, 34095 Montpellier CEDEX 5, France.

\section{References}

1 C.-W. Nan, M. I. Bichurin, S. Dong, D. Viehland and G. Srinivasan, J. Appl. Phys., 2008, 103, 031101-1-031101-35.

2 L. W. Martin, S. P. Crane, Y.-H. Chu, M. B. Holcomb, M. Gajek, M. Huijben, C.-H. Yang, N. Balke and R. Ramesh, J. Phys. Condens. Matter 2008, 20, 434220 (13p).

3 G. Schileo, Prog. Solid State Chem., 2013, 41, 87-98.

4 N. Spaldin and M. Fiebig, Science, 2005, 309, 391-2.

5 G. Srinivasan, Annu. Rev. Mater. Res., 2010, 40, 153-178.

6 W. Eerenstein, N. D. Mathur and J. F. Scott, Nature, 2006, 442, 759-65.

7 A. M. J. G. Van Run, D. R. Terrell and J. H. Scholing, J. Mater. Sci., 1974, 9, $1710-1714$

8 R. A. Islam and S. Priya, J. Mater. Sci., 2009, 44, 5935-5938.

9 J. Ryu, S. Priya, K. Uchino and H. E. Kim, J. Electroceramics, 2012, 8, $107-119$.

10 K. Mori and M. Wuttig, Appl. Phys. Lett., 2002, 81, 100-101

11 Z. Fang, S. G. Lu, F. Li, S. Datta, Q. M. Zhang and M. El Tahchi, Appl. Phys. Lett., 2009, 95, 11-13.

12 H. Zheng, J. Wang, S. E. Lofland, Z. Ma, L. Mohaddes-Ardabili, T. Zhao, L. Salamanca-Riba, S. R. Shinde, S. B. Ogale, F. Bai, D. Viehland, Y. Jia, D. G. Schlom, M. Wuttig, A. Roytburd and R. Ramesh, Science, 2004, 303, 661-663.

13 L. Yan, Y. Yang, Z. Wang, Z. Xing, J. Li and D. Viehland, J. Mater. Sci., 2009, 44, 5080-5094

14 H. Zheng, F. Straub, Q. Zhan, P.-L. Yang, W.-K. Hsieh, F. Zavaliche, Y.H. Chu, U. Dahmen and R. Ramesh, Adv. Mater., 2006, 18, 2747-2752.

15 J. Li, I. Levin, J. Slutsker, V. Provenzano, P. K. Schenck, R. Ramesh, J. Ouyang and A. L. Roytburd, Appl. Phys. Lett., 2005, 87, 072909.

16 F. Yao, L. Xu, B. Lin and G.-D. Fu, Nanoscale, 2010, 2, 1348-1357.

17 J. L. Shuhong Xie, Feiyue Ma, Yuanming Liu, Nanoscale, 2011, 3, 3152 3158.

18 Q. Zhu, Y. Xie, J. Zhang, Y. Liu, Q. Zhan, H. Miao and S. Xie, J. Mater. Res., 2014, 29, 657-664.

19 J. S. Andrew, J. D. Starr and M. a. K. Budi, Scr. Mater., 2014, 74, 38-43.

20 X. Liu, M. Li, Z. Hu, Y. Zhu, S. Dong and X. Zhao, Mater. Lett., 2012, 82, 57-60.

21 X. Z. Zhao and L. X.L, Appl. Phys. A, 2012, 108, 829-834.

22 M. Liu, X. Li, H. Imrane, Y. Chen, T. Goodrich, Z. Cai, K. S. Ziemer, J. Y. Huang and N. X. Sun, Appl. Phys. Lett., 2007, 90, 152501-1 - 1525013.

23 S. H. Johnson, P. Finkel, O. D. Leaffer, S. S. Nonnenmann, K. Bussmann and J. E. Spanier, Appl. Phys. Lett., 2011, 99, 182901-1 - 182901-3.

24 T. N. Narayanan, B. P. Mandal, a K. Tyagi, a Kumarasiri, X. Zhan, M. G. Hahm, M. R. Anantharaman, G. Lawes and P. M. Ajayan, Nano Lett., 2012, 12, 3025-30.

25 D. Sallagoity, C. Elissalde, J. Majimel, R. Berthelot, U. C. Chung, N Penin, M. Maglione, V. a. Antohe, G. Hamoir, F. Abreu Araujo and L. Piraux, J. Mater. Chem. C, 2015, 3, 107-111.

26 S. G. Yang, T. Li, L. S. Huang, T. Tang, J. R. Zhang, B. X. Gu, Y. W. Du, S. Z. Shi and Y. N. Lu, Phys. Lett. A, 2003, 318, 440-444.

27 Z. L. Xiao, C. Y. Han, U. Welp, H. H. Wang, W. K. Kwok, G. a. Willing, J. M. Hiller, R. E. Cook, D. J. Miller and G. W. Crabtree, Nano Lett., 2002, 2, 1293-1297.

28 S.H. Xie, J.Y. Li, Y. Qiao, Y.Y. Liu, L.N. Lan, Y. C. Zhou and S.T. Tan, Appl. Phys. Lett., 2008, 92, 062901-1 - 062901-3

29 Y. Xie, Y. Ou, F. Ma, Q. Yang, X. Tan, and S. Xie, Nanosc. and Nanonotech. Lett., 2013, 5, 546-551.

30 S. Xie, F. Ma, Y. Liu and J. Li, Nanoscale, 2011, 3, 3152-3158.

31 B. A. Hernandez, K. Chang, E. R. Fisher and P. K. Dorhout, Chem. Mater., 2002, 14, 480-482. 
32 S. D. B. Jin Kyu Han, Jongok kim, J. Appl. Phys., 2012, 112, 034106-1 034106-8.

33 A. Encinas-Oropesa, M. Demand, L. Piraux, I. Huynen and U. Ebels, Phys. Rev. B, 2001, 63, 104415-1 - 104415-6.

34 F. Zighem, T. Maurer, F. Ott and G. Chaboussant, J. Appl. Phys., 2011, 109, 013910-1 - 013910-8.

35 L. Qin, G.A. Jones, T. H. Shen, P. J. Grundy, W. X. Li and K. J. Abrams, Mater. Lett., 2010, 64, 2685-2687.

36 F. Wang, H. Huang and S. Yang, J. Eur. Ceram. Soc., 2009, 29, 13871391.

37 S. Prasad and A. Paul, Appl. Phys. Lett., 2007, 90, 2005-2008.

38 G. Ji, S. Tang, B. Xu, B. Gu and Y. Du, Chem. Phys. Lett., 2003, 379, 484-489.

39 Y. Xu, D. S. Xue, D. Q. Gao, J. L. Fu, X. L. Fan, D. W. Guo, B. Gao and W. B. Sui, Electrochim. Acta, 2009, 54, 5684-5687.

40 A. Pirouzfar and S. a. Seyyed Ebrahimi, J. Magn. Magn. Mater., 2014, 370, $1-5$.

41 J.-S. Jung, J.-H. Lim, K.-H. Choi, S.-L. Oh, Y.-R. Kim, S.-H. Lee, D. A. Smith, K. L. Stokes, L. Malkinski and C. J. O'Connor, J. Appl. Phys., 2005, 97, 10F306-1 - 10F306-3 .

42 D. Carlier and J.-P. Ansermet, J. Electrochem. Soc., 2006, 153, C277C281.

43 J. Kim, S. A. Yang, Y. C. Choi, J. K. Han, K. O. Jeong, Y. J. Yun, D. J. Kim, S. M. Yang, D. Yoon, H. Cheong,|K-S. Chang, T. W. Noh and S. D. Bu, Nano Lett., 2008, 8, 1813-1818.

44 Z. Hua, P. Yang, H. Huang, J. Wan, Z.-Z. Yu, S. Yang, M. Lu, B. Gu and Y. Dua, Mat. Chem. Phys., 2008, 107, 541-546.

45 J. E. Spanier, A. M. Kolpak, J. J. Urban, I. Grinberg, L. Ouyang, W. S. Yun, A. M. Rappe and H. Park, Nano Lett., 2008, 6, 735-739. 